\title{
Effects of benzoxazine resin on property enhancement of shape memory epoxy: A dual function of benzoxazine resin as a curing agent and a stable network segment
}

\author{
T. Tanpitaksit ${ }^{1}$, C. Jubsilp ${ }^{2}$, S. Rimdusit ${ }^{*}$ \\ ${ }^{1}$ Polymer Engineering Laboratory, Department of Chemical Engineering, Faculty of Engineering, Chulalongkorn \\ University, 10330 Bangkok, Thailand \\ ${ }^{2}$ Department of Chemical Engineering, Faculty of Engineering, Srinakharinwirot University, 26120 Nakhonnayok, \\ Thailand
}

Received 9 March 2015; accepted in revised form 4 May 2015

\begin{abstract}
An ability of bisphenol-A/aniline based benzoxazine resin (BA-a) to simultaneously acts as a curing agent and a stable or rigid network segment for shape memory epoxy, i.e. a two component system, is demonstrated. This significantly simplifies a formulation of present shape memory epoxy systems, i.e. a three or four component system. A suitable content of BA-a in the aliphatic epoxy (NGDE)/polybenzoxazine (PBA-a) samples for good shape memory performance is in a range of 30 to $50 \mathrm{~mol} \%$. The storage modulus of the obtained NGDE/PBA-a shape memory polymers (SMPs) was increased from $3.57 \mathrm{GPa}$ for $30 \mathrm{~mol} \% \mathrm{BA}$-a content to $4.50 \mathrm{GPa}$ for $50 \mathrm{~mol} \% \mathrm{BA}-\mathrm{a}$ content. Glass transition temperature of the sample was also substantially increased with increasing BA-a fraction, i.e. from $51{ }^{\circ} \mathrm{C}$ to $140^{\circ} \mathrm{C}$. Flexural modulus and strength at room temperature of the samples at $50 \mathrm{~mol} \% \mathrm{BA}$-a were found to be as high as $3.97 \mathrm{GPa}$ and $132 \mathrm{MPa}$ compared to the maximum values of $2.54 \mathrm{GPa}$ and $100 \mathrm{MPa}$ of SMP based on cyanate ester-epoxy. All samples exhibited a high value of shape fixity close to $100 \%$. A presence of the BA-a in the samples also imparted a greater recovery stress ranging from 0.25 to $1.59 \mathrm{MPa}$. Consequently, the obtained NGDE/PBA-a copolymers are highly attractive for shape memory materials to be used in a broader range of applications particularly at elevated temperature and a higher recovery stress value.
\end{abstract}

Keywords: polymer blends and alloys, smart polymer, shape memory polymers, polybenzoxazine, aliphatic epoxy

\section{Introduction}

Shape memory polymers (SMPs) belong to a novel class of smart materials having been a topic of active research since 1980 s, particularly in the past few years [1-7]. They possess an ability to return from a temporary shape to their permanent shape induced by external stimuli such as light, humidity, solvents, electric or magnetic fields, ionic strength, $\mathrm{pH}$ or most typically thermal activation [8]. Interestingly, SMPs have a number of advantages over shape memory metal alloys (SMAs) such as light weight, high elastic deformation with a strain value as high as $200 \%$, a broad range of application temperatures which can be tailored, ease of manipulation, potential biocompatibility and biodegradability as well as cost competitiveness [5, 9]. SMPs have a wide application range in self-deployable structures in spacecraft $[1$, $10]$, orthodontic applications, intelligent medical devices [5,9] or smart textiles and apparels [11]. In general, SMPs can be either thermoplastics, i.e. polyethylene [2] and polyester [5] or thermosetting polymers such as epoxy $[12,13]$ or polyurethane $[14$, 15]. In case of SMP thermoplastics, their networks can be constructed with physical crosslinks by physical interactions. This characteristic will allow very easy reshaping or re-formation of this class of poly-

\footnotetext{
${ }^{*}$ Corresponding author, e-mail: sarawut.r@chula.ac.th

(c) BME-PT
} 
mers. However, they can potentially melt at high temperature, and lose their memory properties over time [16]. Contrarily, chemical crosslinks by covalent bonds can be formed for thermoset SMPs; they soften but do not melt at elevated temperature [4, 17]. As a consequence, thermosetting SMPs, especially epoxybased SMPs, have been highly attractive particularly in advanced applications $[13,18,19]$. To further broaden the useful property range of shape memory epoxy, epoxy-based shape memory copolymers and epoxy-based shape memory composites have also been developed [18-21]. Recently, Xie and Rousseau [20] had developed methods to tailor transition temperature $\left(T_{\mathrm{g}}\right)$ and shape recovery properties of SMPs based on aromatic epoxy as hard segments, aliphatic epoxy as soft segments and aliphatic amine as curing agents. The authors reported that all of their crosslinked epoxy samples showed good SMP characteristics, including excellent shape fixity with shape recovery close to $100 \%$ as well as easily tailored thermal transition temperatures ranging from room temperature to $89^{\circ} \mathrm{C}$. However, in polymerization step of oxirane group containing epoxy, the resin requires a suitable curing agent. In general, epoxy curing agents, i.e. aromatic amines possess some drawbacks such as relatively low elongation and rather slowly curing for epoxy resin as well as serious toxicity concerning in some cases and corrosion to the processing apparatus [22]. In addition, they show no direct benefit to the shape memory performance of the obtained shape memory epoxy.

Benzoxazine resin, a novel class of thermosetting phenolics [23], has been developed in 1990s to solve various inherent problems occurred in traditional phenolics. For example, the resin can undergo ringopening polymerization upon heating without strong acid or base catalysts; therefore, no condensation byproduct is released during a curing process. This eliminates the formation of voids or air gaps in the fully cured products that normally occur in phenolic resin. A very low A-stage viscosity of the resin results in its high processing ability including ease of filler wetting and high filler loadings [24-26]. The polymer from this resin has been reported to show high thermal stability, excellent mechanical performance, good dimensional stability and relatively high glass transition temperature even though they exhibit relatively low crosslinking density [23, 27, 28]. More importantly, the benzoxazine resin has been shown to be able to blend with various types of resins or polymers to provide even broader spectrum of the copolymer properties. As exemplified, benzoxazine resin had been shown to be able to function as a latent curing agent for epoxy resin and, in some cases, provide synergism in thermal and mechanical properties of the obtained benzoxazine/epoxy copolymers [27, 29-31]. Very recently, shape memory polymers between bisphenol-A/aniline based benzoxazine resin (BA-a) and shape memory polyurethane (SMPU) have been investigated by Erden and Jana [32]. From their investigation, the authors suggested that the BA-a can be either chemically bonded with SMPU chains by copolymerization or grafting reactions or blended with SMPU as a separate phase. Furthermore, the polybenzoxazine (PBA-a) can act as an additional hard phase for the SMPU due to its higher glass transition temperature and much greater storage modulus than the soft segment phase of the SMPU. An addition with only $17 \mathrm{wt} \%$ of the BA-a in the SMPU rendered a recovery stress and shape recovery ratio as high as $13 \mathrm{MPa}$ and $93 \%$, which was substantially higher than those of the starting SMPU, i.e. $6.8 \mathrm{MPa}$ and $72 \%$. In addition, Rimdusit et al. [7] have recently developed shape memory polymer copolymers based on bisphenol-A/ aniline based benzoxazine resin (BA-a), aliphatic-aromatic epoxy mixture, and Jeffamine D230 as the epoxy curing agent. Enhanced thermomechanical performance of the obtained epoxy SMPs was achieved by an addition of the BA-a fraction. The incorporation of the BA-a contributed to higher storage modulus in the glassy state, higher crosslink density, enhanced flexural strength, and greater flexural modulus at room temperature. Moreover, the recovery stress of the obtained SMPs was reported to increase with increasing BA-a content up to $33 \mathrm{~mol} \%$ with the reported recovery stress of about $38 \mathrm{kPa}$. It was 1.8 times higher comparing with $20.4 \mathrm{kPa}$ of the unmodified shape memory epoxy.

The purpose of this study is to investigate the potential use of bisphenol-A/aniline based benzoxazine resin (BA-a) as a sole curing agent for aliphatic shape memory epoxy. Moreover, it is expected that the aromatic structure of the BA-a can act as a hard or stable phase for the aliphatic epoxy network thus eliminate the need for aromatic epoxy that is normally added in typical shape memory epoxy products. Twofold benefits are expected from this aliphatic epoxy/benzoxazine SMPs, i.e. (1) a potential improvement of thermomechanical properties and 
recovery stress of the copolymer samples with an addition of the more rigid polybenzoxazine and (2) a simpler shape memory epoxy formulation from the dual function of the BA-a above. Some essential properties, such as glass transition temperature, flexural modulus, flexural strength, recovery stress and shape recovery performance will also be investigated.

\section{Experimental}

\subsection{Materials}

Materials used in this study was bisphenol-A/anilinebased benzoxazine resin (BA-a). The BA-a was synthesized according to the solventless technology $[23,33]$. Bisphenol-A (polycarbonate grade) was provided by Thai Polycarbonate Co., Ltd. (Rayong, Thailand). Para-formaldehyde (AR grade) and aniline (AR grade) was purchased from Merck Co., Ltd. (Darmstadt, Germany) and Panreac Quimica, S.A. (Barcelona, Spain), respectively. Aliphatic epoxy (Neopentyl glycol diglycidyl ether; NGDE) was available from Aditya Birla Chemicals Thailand Ltd. (Rayong, Thailand). All chemicals were used as received. The NGDE/BA-a mixtures at different mole percent of the BA-a varied from 30 to $50 \mathrm{~mol} \%$ were prepared. The mixture was heated at about $80^{\circ} \mathrm{C}$ in an aluminum pan and stirred for about $15 \mathrm{~min}$ to yield a homogeneous mixture. The molten resin was poured into an aluminum mold and was thermally cured at $80^{\circ} \mathrm{C}$ for $2 \mathrm{~h}$ in vacuum oven and $130^{\circ} \mathrm{C} / 12 \mathrm{~h}, 140^{\circ} \mathrm{C} / 4 \mathrm{~h}, 150^{\circ} \mathrm{C} / 4 \mathrm{~h}$ and $160^{\circ} \mathrm{C} / 2 \mathrm{~h}$, respectively, in an air circulated oven. Then, the cured NGDE/polybenzoxazine (PBA-a) shape memory samples were cut into various shapes for each specific test.

\subsection{Characterization methods}

Curing behaviors of the BA-a, NGDE and NGDE/ BA-a mixtures were studied using a differential scanning calorimeter (DSC) model 2910 from TA Instruments (New Castle, DE, United States). Each sample with a mass in a range of 3-5 mg was sealed in an aluminum pan with lid. The heating rate used was 5 and $10^{\circ} \mathrm{C} / \mathrm{min}$ and the sample temperature was scanned from room temperature to $320^{\circ} \mathrm{C}$ under nitrogen purging with the gas flow rate of $50 \mathrm{~mL} / \mathrm{min}$. The degree of conversion of a sample was determined according to the relationship in Equation (1):
Conversion $[\%]=\left(1-\frac{H_{\mathrm{rxn}}}{H_{0}}\right) \cdot 100$

where $H_{\mathrm{rxn}}$ is the heat of reaction of the partially cured samples and $H_{0}$ is the heat of reaction of the uncured resin mixture.

Chemical structure and network formation of all samples was studied by a Fourier transform infrared spectroscopy (FTIR), a Spectrum GX FT-IR spectometer from Perkin Elmer with an ATR accessory (Waltham, Massachusetts, United States). All spectra were taken as a function of time with 64 scans at a resolution of $4 \mathrm{~cm}^{-1}$ and wavenumber ranging from $4000-650 \mathrm{~cm}^{-1}$. For viscous liquid NGDE/BA-a mixtures, a small amount of mixture was casted as thin film on a potassium bromide $(\mathrm{KBr})$ window and its FTIR spectrum was obtained.

Dynamic mechanical analyzer (DMA) model DMA242 from Netzsch, Inc. (Bavaria, Germany) was used to determine a storage modulus $\left(E^{\prime}\right)$ and loss tangent $(\tan \delta)$ of the NGDE/PBA-a shape memory samples. The sample in rectangular shape, with a dimension of $10 \mathrm{~mm} \times 50 \mathrm{~mm} \times 3 \mathrm{~mm}$, was tested using a three-point bending mode with $40 \mathrm{~mm}$ supporting span at the frequency of $1 \mathrm{~Hz}$ and a heating rate of $2^{\circ} \mathrm{C} / \mathrm{min}$ from room temperature to the temperature beyond the glass transition temperatures ( $T_{\mathrm{g}}$ ) of each sample. The $T_{\mathrm{g}}$ was taken as the maximum peak on the loss tangent curve in the DMA thermogram.

Flexural properties of NGDE/PBA-a shape memory samples were measured according to ASTM D 790M using a universal testing machine (model 5567) from Instron (Thailand) Co., Ltd. (Bangkok, Thailand). The test method was a three-point bending load with a supporting span of $32 \mathrm{~mm}$ and tested at a crosshead speed of $1.0 \mathrm{~mm} / \mathrm{min}$. A dimension of a rectangular shape sample was $10 \mathrm{~mm} \times 50 \mathrm{~mm} \times 2 \mathrm{~mm}$.

A systematic shape recovery test of NGDE/PBA-a shape memory samples under bending load was also performed. The procedure for the thermomechanical bending cycling of NGDE/ PBA-a shape memory samples includes the following steps: firstly, the sample in its permanent shape was kept in an oven for $20 \mathrm{~min}$ at $T_{\mathrm{g}}+20^{\circ} \mathrm{C}$; then the sample was bent to a storage angle $\theta_{0}$ in a ' $U$ ' shape with the radius of $2 \mathrm{~mm}$ in the soft rubbery state, after that the sample was kept at room temperature with the external con- 
straint to freeze the elastic deformation energy for $20 \mathrm{~min}$. The sample fixed on the apparatus was then immersed into air circulated oven at elevated temperature, and it recovered to an angle $\theta_{\mathrm{N}}$ [34]. The value of the shape recovery ratio $\left(R_{\mathrm{N}}\right)$ can be calculated by Equation (2):

$R_{\mathrm{N}}=\frac{\theta_{0}-\theta_{\mathrm{N}}}{\theta_{0}} \cdot 100 \%$

Shape fixity and recovery stress of NGDE/PBA-a shape memory samples were studied by a universal testing machine under three point bending mode. The experimental procedure for the shape fixity and recovery stress was performed using the same method as described in [35]. Firstly, a fixed shape was formed by applying force to a sample $(10 \mathrm{~mm} \times 50 \mathrm{~mm} \times$ $2 \mathrm{~mm}$ ) at $T_{\mathrm{g}}+20^{\circ} \mathrm{C}$ and left to cool down to room temperature. The force was then removed completely to obtain a temporary shape. The deflection after unloading was then measured, and shape fixity $\left(R_{\mathrm{f}}\right)$ of each sample was determined. In addition, the sample was also heated up to $T_{\mathrm{g}}+20^{\circ} \mathrm{C}$ by keeping the fixed deflection content, afterwards, deflection force of each sample during heating was measured and the coresponding recovery stress was obtained.

\section{Results and discussion}

\subsection{Effects of $B A-a$ contents on curing behaviors of NGDE/BA-a mixtures}

Curing characteristics of aliphatic epoxy (NGDE)/ benzoxazine resin (BA-a) mixtures at BA-a contents of 30,40 and $50 \mathrm{~mol} \%$ were studied by a differential scanning calorimeter (DSC) at a heating rate $5^{\circ} \mathrm{C} / \mathrm{min}$ as shown in Figure 1. The thermogram of the BA-a showed a curing exothermic peak located at about $210^{\circ} \mathrm{C}$, while the NGDE showed no sign of any curing reaction in this temperature range because no initiators or catalysts were added to the resin. Instead the endothermic thermal event starting at about $200^{\circ} \mathrm{C}$ a result of the evaporation process of the NGDE was observed. For the NGDE/BA-a mixtures, the thermograms revealed three exothermic peaks of these resin mixtures. The two overlapping peaks at lower temperature were found to be in a range of $235-240^{\circ} \mathrm{C}$ whereas the third peak at high temperature were observed at temperature about $275-285^{\circ} \mathrm{C}$. Both peaks tended to shift to higher temperature with increasing epoxy content. The phenomenon is attributed to diluent effect of the liquid epoxy on benzoxazine curing [29]. Furthermore, the

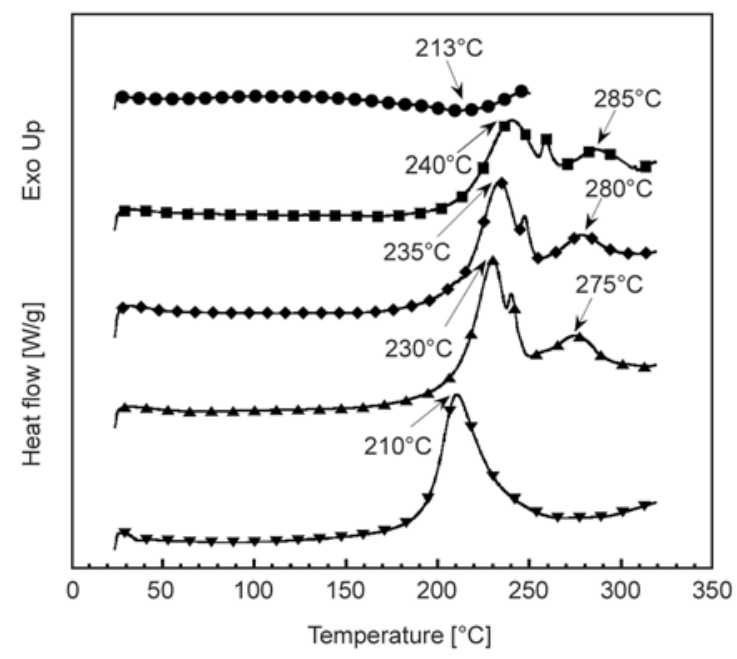

Figure 1. DSC thermograms of NGDE/BA-a mixtures at various mole percents of BA-a: $(\bullet) \mathrm{NGDE}$, (ロ) $30 \mathrm{~mol} \%, \quad$ (•) $40 \mathrm{~mol} \%$, (४ $50 \mathrm{~mol} \%$, ( v) BA-a

reactions between the BA-a and the NGDE were found to comprise of at least two major reactions. The first reaction at the two overlapping exothermic peak at lower temperature is attributed to the polymerization reaction of the BA-a monomers, whereas the third exothermic peak at a higher temperature is the reaction between the phenolic hydroxyl group of the polybenzoxazine (PBA-a) and the epoxide group of the NGDE. This result is in good agreement with the curing behaviors of bisphenol-A based epoxy by the BA-a $[29,36]$.

Figure 2 illustrates DSC thermograms at a heating rate $10^{\circ} \mathrm{C} / \mathrm{min}$ of the NGDE/BA-a mixture at $50 \mathrm{~mol} \%$ of the BA-a content at various curing conditions. The optimal curing conditions of the NGDE/ BA-a mixtures were determined from the partial disappearance of the area under the curve of the exothermic peak in the DSC experiment. The heat of reaction of the uncured sample was measured to be $272.0 \mathrm{~J} / \mathrm{g}$. After a step curing at $130^{\circ} \mathrm{C} / 12 \mathrm{~h}$, $140^{\circ} \mathrm{C} / 4 \mathrm{~h}, 150^{\circ} \mathrm{C} / 4 \mathrm{~h}$ and $160^{\circ} \mathrm{C} / 2 \mathrm{~h}$, the values decreased to $245.6,236.7,231.7$ and $101.4 \mathrm{~J} / \mathrm{g}$, respectively, which corresponded to the degree of conversion of 9.7, 12.9, 14.8 and $62.7 \%$. Liu et al. [37] suggested that the degree of conversion about $60 \%$ of shape memory epoxy provided samples with good balance properties between shape memory performance and thermomechanical properties. The fully cured samples, i.e. $100 \%$ conversion, were reported to give samples with too high crosslink density thus resulting in great reduction in molecular chain mobility and poorer shape memory perform- 


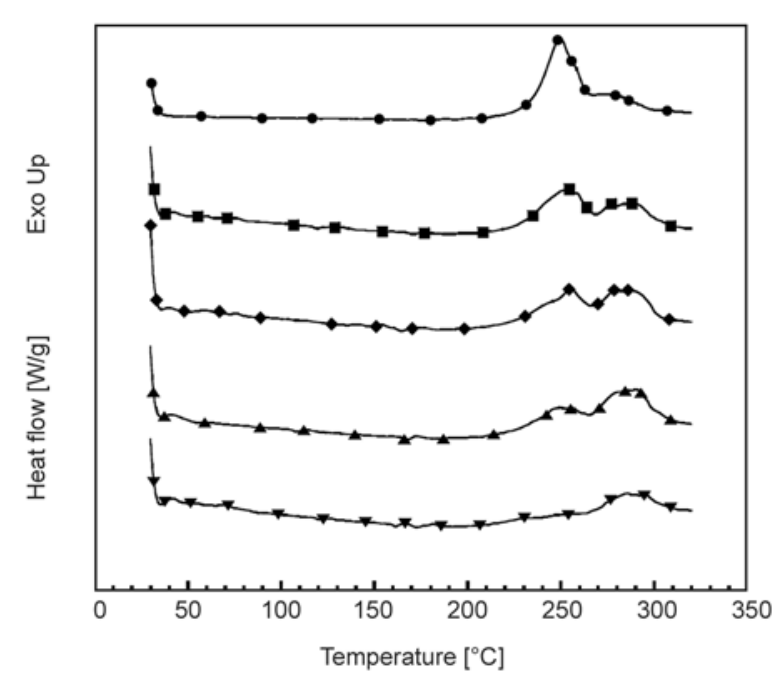

Figure 2. DSC thermograms of NGDE/BA-a samples at $50 \mathrm{~mol} \% \mathrm{BA}-\mathrm{a}$ at various curing conditions: (•) uncured, (-) $130^{\circ} \mathrm{C} / 12 \mathrm{~h},(\diamond) 130^{\circ} \mathrm{C} / 12 \mathrm{~h}+$ $140^{\circ} \mathrm{C} / 4 \mathrm{~h}, \quad$ ( $) 130^{\circ} \mathrm{C} / 12 \mathrm{~h}+140^{\circ} \mathrm{C} / 4 \mathrm{~h}+$ $150^{\circ} \mathrm{C} / 4 \mathrm{~h}, \quad$ ( $) 130^{\circ} \mathrm{C} / 12 \mathrm{~h}+140^{\circ} \mathrm{C} / 4 \mathrm{~h}+$ $150^{\circ} \mathrm{C} / 4 \mathrm{~h}+160^{\circ} \mathrm{C} / 2 \mathrm{~h}$

ance. Therefore, the curing process under the above step cure conditions to achieve approximately $60 \%$ conversion was used in our work to cure all NGDE/ BA-a mixtures preparing the NGDE/PBA-a shape memory samples for further characterizations.

\subsection{Fourier transform infrared spectroscopy (FTIR) of BA-a/NGDE network formation}

Chemical structures of benzoxazine resin (BA-a), aliphatic epoxy (NGDE) and their network formation were studied by FTIR spectroscopy. Figure 3 shows FTIR spectra taken from the BA-a, the NGDE and the NGDE/BA-a mixture at $50 \mathrm{~mol} \% \mathrm{BA}-\mathrm{a}$. The characteristic IR absorption bands of the BA-a were found at $1230 \mathrm{~cm}^{-1}$ assigned to $\mathrm{C}-\mathrm{O}-\mathrm{C}$ stretching mode of benzene ring and 1496 and $936 \mathrm{~cm}^{-1}$ assigned to tri-substituted benzene ring as shown in Figure 3 curve a $[23,38]$. The IR absorption bands of the NGDE were observed at $1098 \mathrm{~cm}^{-1}$ assigned to $\mathrm{C}-\mathrm{O}-\mathrm{C}$ stretching mode of ethers as well as the peaks at 1254, 909 and $850 \mathrm{~cm}^{-1}$ assigned to epoxide ring mode [33] as depicted in Figure 3 curve b. In Figure 3 curve c, it was evidently confirmed by FTIR that the NGDE/BA-a mixture contained both BA-a and NGDE characteristic IR absorptions, such as those at 1496 and $936 \mathrm{~cm}^{-1}$ from the BA-a species and that of 1254,909 and $850 \mathrm{~cm}^{-1}$ from epoxide ring of the NGDE.

The network formation between the BA-a and the NGDE after thermal cure were also monitored by

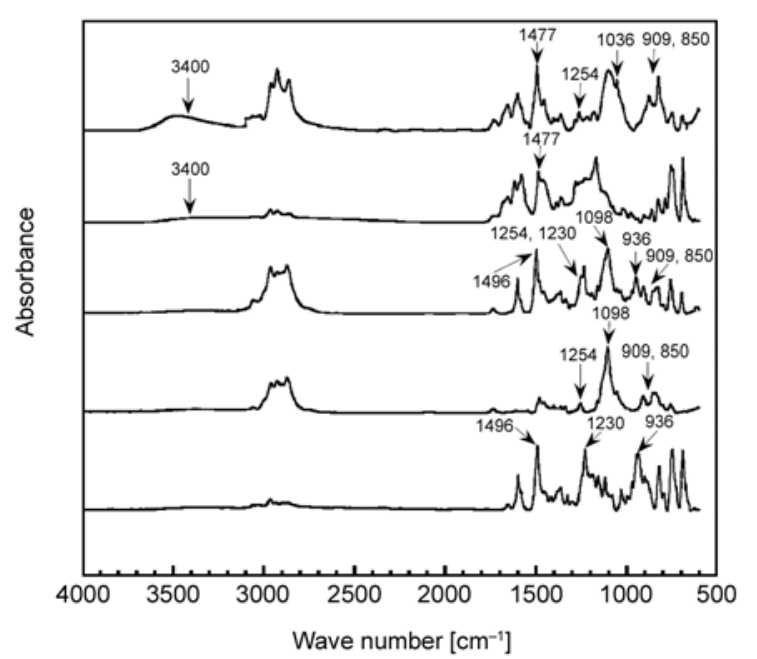

Figure 3. FTIR spectra of (a) BA-a, (b) NGDE, (c) NGDE/ BA-a mixture at $50 \mathrm{~mol} \% \mathrm{BA}-\mathrm{a}$, (d) PBA-a, (e) NGDE/PBA-a copolymer at $50 \mathrm{~mol} \% \mathrm{BA}-\mathrm{a}$

FTIR. Figures $3 \mathrm{a}$ and $3 \mathrm{~d}$ showed FTIR spectra taken from the BA-a and the polybenzoxazine (PBA-a). For BA-a polymerization process, the oxazine ring was opened by the breakage of a $\mathrm{C}-\mathrm{O}$ bond of the ring. Then, the BA-a molecules were transformed from a ring structure to a network structure. During this process, the tri-substituted benzene ring, backbone of BA-a ring, became tetra-substituted benzene ring $[23,38]$. The ring-opening polymerization of the BA-a was observed from the decrease of the absorption bands at 1496 , and $936 \mathrm{~cm}^{-1}$ and the appearance of the new absorption band at $1477 \mathrm{~cm}^{-1}$ of the tetra-substituted benzene ring. In addition, a broad intensive IR absorption band appeared at $3400 \mathrm{~cm}^{-1}$ was assigned to $\mathrm{O}-\mathrm{H}$ groups of the phenolic hydroxyl group that can react with epoxide group in the NGDE for ring opening polymerization. Moreover, the FTIR spectra of the NGDE/BAa mixture at $50 \mathrm{~mol} \% \mathrm{BA}$-a before and after polymerization were also shown in Figures $3 \mathrm{c}$ and $3 \mathrm{e}$. After being step cured at $160^{\circ} \mathrm{C}$ for $2 \mathrm{~h}$. The absorption band at $1477 \mathrm{~cm}^{-1}$ of the PBA-a was also found in the NGDE/PBA-a copolymers whereas the absorption bands at 1254 (vibration modes), 909 and $850 \mathrm{~cm}^{-1}$ (asymmetric stretching) assigned to the remained epoxide group appeared. Therefore, it can be suggested that epoxide groups can react with the phenolic hydroxyl group of the ring opened BA-a monomers to form new ether linkages and hydroxyl groups in epoxy moieties [39] as clearly seen the absorption bands at 1036 and $3400 \mathrm{~cm}^{-1}$, respectively, in Figure 3 curve e. A possible chemical reaction 


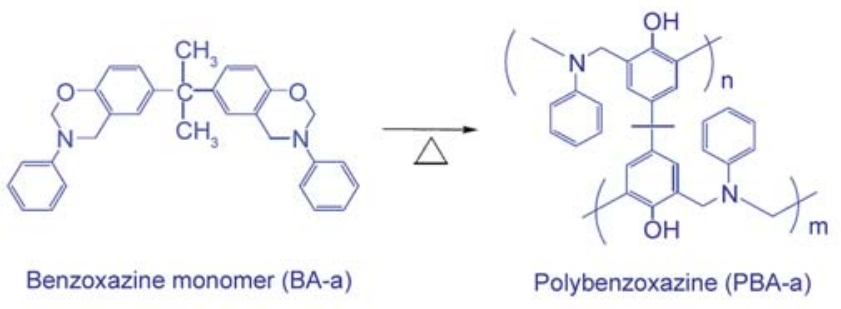

a)
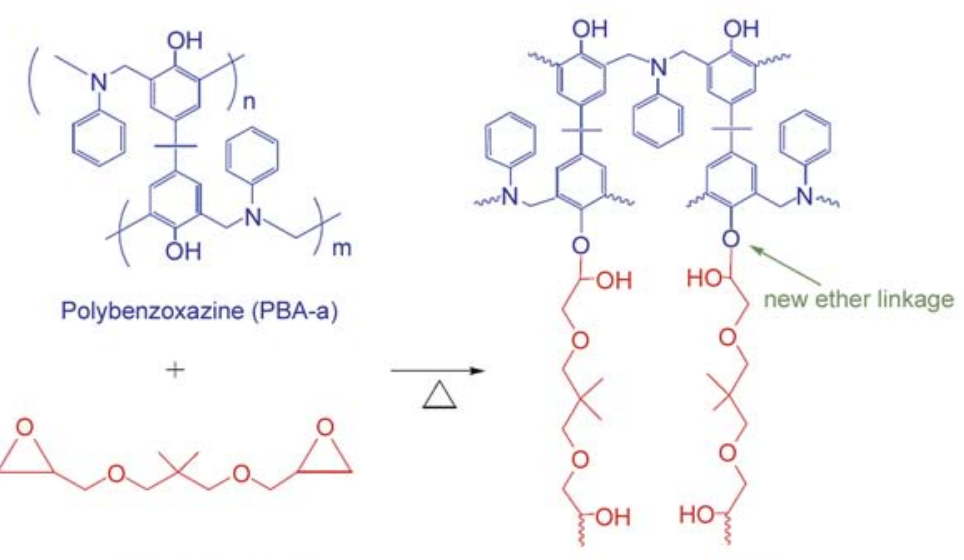

Aliphatic epoxy (NGDE)

b)

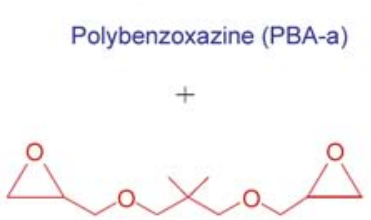

NGDE/PBA-a copolymer

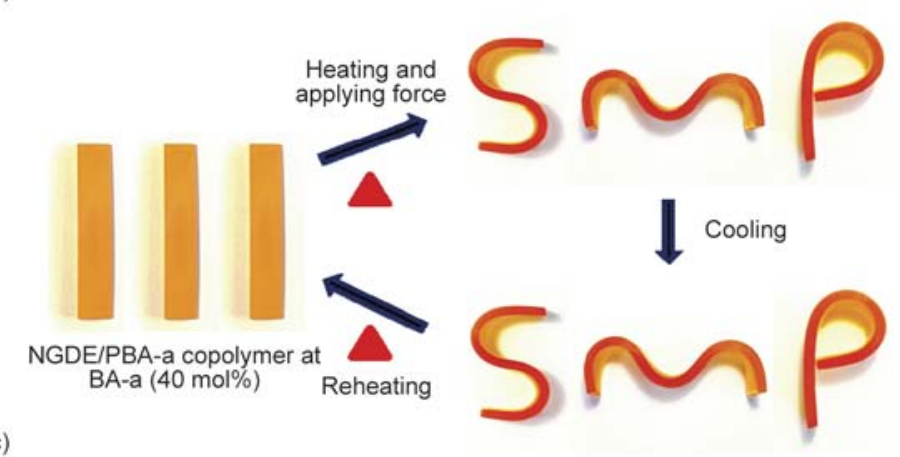

Figure 4. (a) Curing reaction of BA-a, (b) A possible chemical reaction between PBA-a and NGDE and (c) NGDE/PBA-a SMP at original shape, temporary shape and recovered shape at $T_{\mathrm{g}}+20^{\circ} \mathrm{C}$

between the BA-a and the NGDE is shown in Figure 4. It was postulated that the BA-a ring was opened by heating at suitable temperature (Figure 4a). The phenolic hydroxyl groups of the ring opened the BA-a monomer then acted as an epoxy curing agent to open the epoxide ring to form the ether linkages in the copolymer networks as proposed in Figure 4b. These results are also in good agreement with the previous reports by our research group [30,36] and Kimura et al. [31] using different types of epoxy resins.

\subsection{Dynamic mechanical analysis of NGDE/PBA-a SMPs}

Viscoelastic properties served as one key characterization for screening the series of NGDE/PBA-a shape memory polymers (SMPs) for good shape- memory performance. Figure 5 and Figure 6 displays the temperature-dependence of storage modulus $\left(E^{\prime}\right)$ and loss tangent $(\tan \delta)$ of the aliphatic epoxy (NGDE)/polybenzoxazine (PBA-a) shape memory samples. From Figure 5, the storage moduli at a glassy state $\left(35^{\circ} \mathrm{C}\right)$ of the NGDE/PBA-a SMPs at BA-a contents of $30,35,40,45$ and $50 \mathrm{~mol} \%$ were measured to be $3.57,3.79,3.92,4.29$ and $4.50 \mathrm{GPa}$, respectively. From the results, the storage moduli of the samples tended to increase with increasing BA-a content. The phenomenon is attributed to the addition of the more rigid molecular segments of the PBA-a in the NGDE/PBA-a shape memory samples. Moreover, to obtain the optimum performance for a shape-memory polymer, the drop in modulus should not only be large and sharp but it should ideally be followed by an extended rubbery plateau 


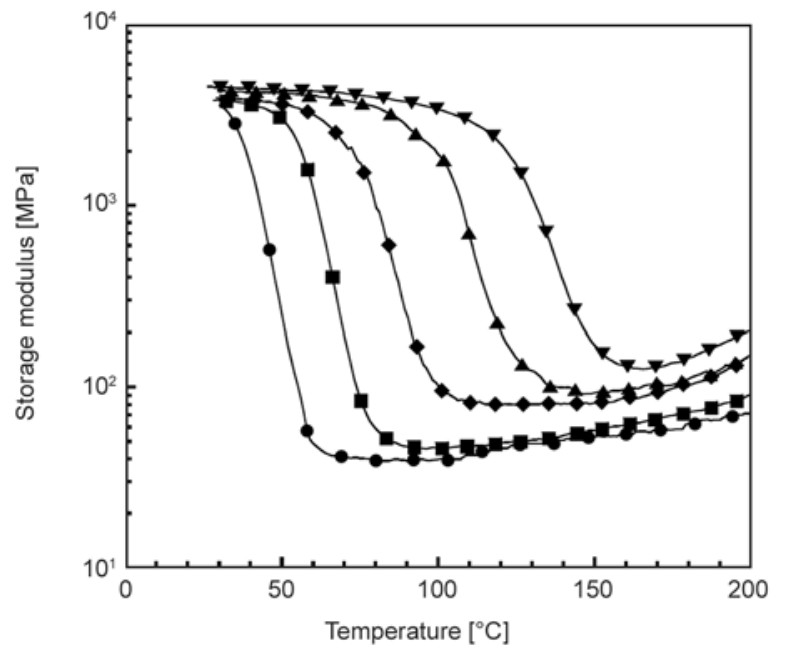

Figure 5. Storage modulus versus temperature of NGDE/ PBA-a SMPs at various mole percents of BA-a: (•) $30 \mathrm{~mol} \%$, (ロ) $35 \mathrm{~mol} \%, \quad$ (•) $40 \mathrm{~mol} \%$, (४) $45 \mathrm{~mol} \%$, ( $\mathbf{v}) 50 \mathrm{~mol} \%$

[40]. As seen in Figure 5, the addition of the BA-a also resulted in a systematic increase of the modulus in rubbery plateau region from 40 to $172 \mathrm{MPa}$. This characteristic suggested the BA-a to be an effective crosslinker for the aliphatic epoxy. In addition, we can see that a difference of two orders of magnitude of the high elasticity ratio between glassy state modulus $\left(E_{\mathrm{g}}\right)$ and rubbery modulus $\left(E_{\mathrm{r}}\right)$ was obtained in the SMPs. Therefore, the NGDE/PBA-a SMPs are easy shaping at $T>T_{\mathrm{S}}$ (shape memory temperature) and they show great resistance to deformation at $T<T_{\mathrm{s}}[41]$.

Loss tangent $(\tan \delta)$ curves from a DMA experiment of the NGDE/PBA-a SMPs at various BA-a contents are depicted in Figure 6. The peak positions of the $\tan \delta$ were used to indicate $T_{\mathrm{g}}$ of the samples. We can see that, an increase of the BA-a content in the NGDE/PBA-a SMPs resulted in a systematic increase in the $T_{\mathrm{g}}$ of the samples. The $T_{\mathrm{g}}$ of the NGDE/PBA-a samples were $51^{\circ} \mathrm{C}$ for $30 \mathrm{~mol} \% \mathrm{BA}-\mathrm{a}, 70^{\circ} \mathrm{C}$ for $35 \mathrm{~mol} \% \mathrm{BA}-\mathrm{a}, 88^{\circ} \mathrm{C}$ for $40 \mathrm{~mol} \% \mathrm{BA}-\mathrm{a}, 122^{\circ} \mathrm{C}$ for $45 \mathrm{~mol} \% \mathrm{BA}-\mathrm{a}$ and $140^{\circ} \mathrm{C}$ for $50 \mathrm{~mol} \%$ BA-a. As a consequence, a wide range of the $T_{\mathrm{g}}$ from 51 to $140^{\circ} \mathrm{C}$ allowing relatively wide range of service temperature was obtained in these NGDE/PBA-a SMPs. This behavior was attributed to the more rigid molecular structure of the polybenzoxazine compared to the epoxy [42]. Moreover, the peak height of the $\tan \delta$ corresponding to the strain energy dissipated by viscous friction was observed to decrease with increasing mole percent of the BA-a which suggested the elastic behavior of the NGDE/PBA-a

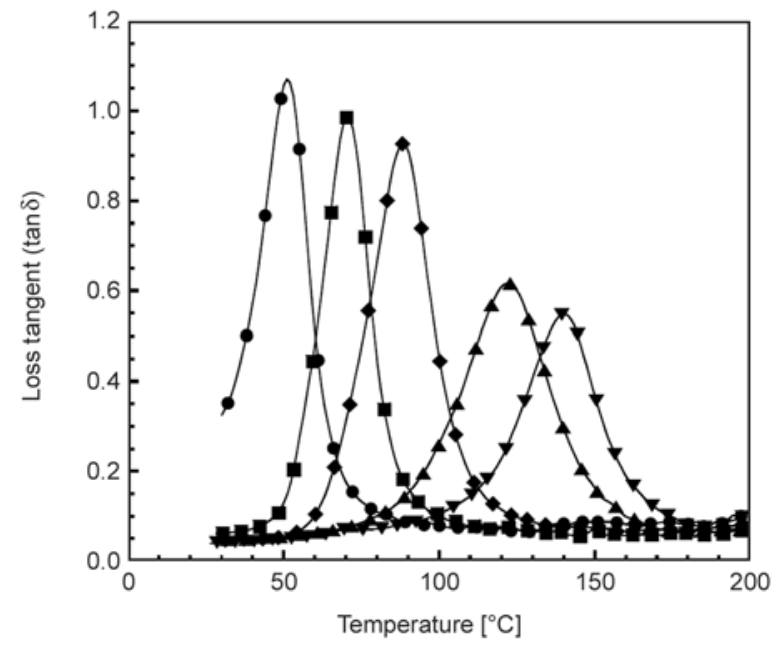

Figure 6. Loss tangent versus temperature of NGDE/PBA-a SMPs at various mole percents of BA-a: (•) $30 \mathrm{~mol} \%, \quad$ (•) $35 \mathrm{~mol} \%$, (•) $40 \mathrm{~mol} \%$, (ム) $45 \mathrm{~mol} \%$, ( $\mathbf{v}) 50 \mathrm{~mol} \%$

SMPs to be enhanced with the amount of the BA-a crosslinker. We also observed a broader width at half height of the curves which implied network heterogeneity to be more pronounced when the amount of the BA-a increased. However, the transparency and the single peak of $\tan \delta$ of each sample confirmed the single microscopic domain of the NGDE/PBA-a SMPs implying no phase separation in these copolymers. The single broad $T_{\mathrm{g}}$ or switching transition is desirable in some special cases of shape memory polymers such as in multiple shape memory polymers (MSMPs). Moreover, our samples also showed a relatively broad $T_{\mathrm{g}}$ range covering that of the commercially available epoxy-based shape memory polymer, i.e. Veriflex ${ }^{\circledR} \mathrm{E}\left(T_{\mathrm{g}}=62^{\circ} \mathrm{C}\right)$ and styrenebased shape memory polymer, i.e. Veriflex ${ }^{\circledR}\left(T_{\mathrm{g}}=\right.$ $90^{\circ} \mathrm{C}$ ) from Cornerstore Industries [43].

\subsection{Mechanical properties of NGDE/PBA-a SMPs}

Mechanical properties, i.e. flexural strength $\left(\sigma_{\mathrm{f}}\right)$ and modulus $\left(E_{\mathrm{f}}\right)$ at room temperature of the aliphatic epoxy (NGDE)/polybenzoxazine (PBA-a) SMPs as a function of BA-a content were examined as plotted in Figure 7. It can be seen that the flexural strength of the samples increased with an increase in the amount of the BA-a. The flexural strength of the samples were measured to be $52 \mathrm{MPa}$ for $30 \mathrm{~mol} \%$ BA-a, $78 \mathrm{MPa}$ for $35 \mathrm{~mol} \% \mathrm{BA}-\mathrm{a}, 108 \mathrm{MPa}$ for $40 \mathrm{~mol} \% \mathrm{BA}-\mathrm{a}, 124 \mathrm{MPa}$ for $45 \mathrm{~mol} \% \mathrm{BA}-\mathrm{a}$, and $132 \mathrm{MPa}$ for $50 \mathrm{~mol} \% \mathrm{BA}-\mathrm{a}$. This characteristic was due to the addition of high flexural strength PBA-a, 


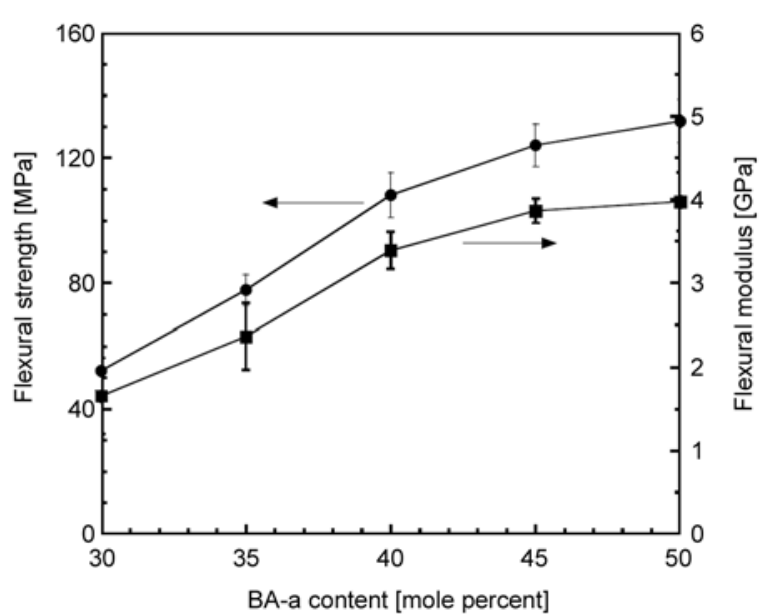

Figure 7. Flexural strength $(\bullet)$ and flexural modulus $(\boldsymbol{\square})$ at room temperature $\left(25^{\circ} \mathrm{C}\right)$ of NGDE/PBA-a SMPs at various mole percents of BA-a

i.e. $\sigma_{\mathrm{f}} \sim 126-139 \mathrm{MPa}[44]$ and chemical linkage formation between PBA-a with the epoxy network. The NGDE/PBA-a SMPs also rendered flexural strength higher than that of cyanate ester-epoxy shape memory samples, i.e. 14-100 MPa [45]. Moreover, an addition of the BA-a into the NGDE was expectedly found to improve flexural modulus of the NGDE/ PBA-a SMPs, i.e. $1.6 \mathrm{GPa}$ for BA-a $=30 \mathrm{~mol} \%$ to 4.0 GPa for $\mathrm{BA}-\mathrm{a}=50 \mathrm{~mol} \%$ as also seen in Figure 7 . This is due to the addition of the more rigid PBA-a, i.e. $E_{\mathrm{f}} \sim 4.5-5.8 \mathrm{GPa}[44]$ into the more flexible aliphatic epoxy as well as an enhanced crosslink density of the obtained polymer network described previously.

The potential applications in deployable structure of the NGDE/PBA-a SMPs were systematic investigated by flexural testing in the rubbery state $\left(T_{\mathrm{g}}+20^{\circ} \mathrm{C}\right)$. In this work, the flexural testing was carried out on the universal testing machine equipped with the environmental chamber at $T_{\mathrm{g}}+20^{\circ} \mathrm{C}$. Figure 8 displayed a plot of flexural strength at $T_{\mathrm{g}}+20^{\circ} \mathrm{C}$ of the NGDE/PBA-a SMPs at different BA-a contents. The flexural strength at a rubbery state of the samples with BA-a contents of 30,35 , 40,45 and $50 \mathrm{~mol} \%$ were measured to be $0.4,0.6$, $0.9,1.5$ and $2.3 \mathrm{MPa}$, respectively. From the results, the flexural strength at the rubbery state of the samples increased with increasing amount of BA-a similar to what observed in the strength at room temperature. The greater values of flexural strength at the rubbery state of the samples are attributed to the enhancement of crosslink density of the samples as discussed in DMA experiment. The flexural strength at the rubbery state of our NGDE/PBA-a SMPs at

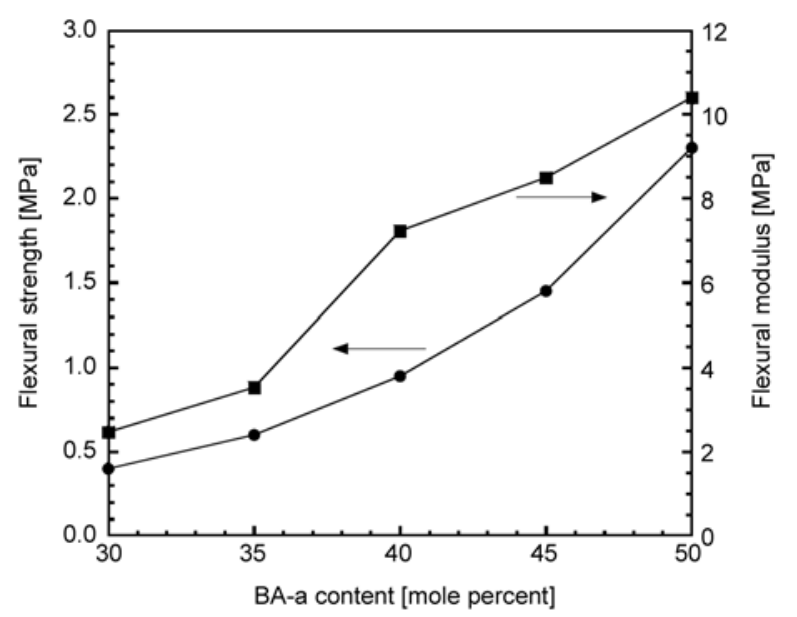

Figure 8. Flexural strength $(\bullet)$ and flexural modulus $(\boldsymbol{\bullet})$ at $T_{\mathrm{g}}+20^{\circ} \mathrm{C}$ of NGDE/PBA-a SMPs at various mole percents of $\mathrm{BA}-\mathrm{a}$

$50 \mathrm{~mol} \% \mathrm{BA}-\mathrm{a}$ is about 10 times higher than commercial SMPs based on styrene resin $\left(\right.$ Veriflex ${ }^{\circledR}$ ), i.e. $0.23 \pm 0.03 \mathrm{MPa}$ [46]. Furthermore, the effects of BA-a contents on flexural modulus at $T_{\mathrm{g}}+20^{\circ} \mathrm{C}$ of the shape memory samples are illustrated in Figure 8. The addition of the BA-a into the NGDE was found to increase flexural modulus at $T_{\mathrm{g}}+20^{\circ} \mathrm{C}$ of the samples. The flexural modulus of the samples were ranging from $2.5 \mathrm{MPa}$ for $30 \mathrm{~mol} \% \mathrm{BA}-\mathrm{a}$, up to 10.4 MPa for $50 \mathrm{~mol} \% \mathrm{BA}-\mathrm{a}$. The obtained values are in a same range as that of a commercial thermoset SMP epoxy system (DP7AR), i.e. $E_{\mathrm{f}}$ at $T_{\mathrm{g}}+20^{\circ} \mathrm{C}$ $=8.51 \mathrm{MPa}$ [12] and a commercial SMPs based on styrene resin $\left(\right.$ Veriflex $\left.^{\circledR}\right)$, i.e. $6.48 \pm 1.71 \mathrm{MPa}$ [46].

\subsection{Effect of BA-a contents on shape fixity of NGDE/PBA-a SMPs}

Shape fixity $\left(R_{\mathrm{f}}\right)$ is one important shape memory performance indicating an ability to memorize temporary shape of shape memory polymers (SMPs). When SMPs is heated to a temperature above its glass transition temperature $\left(T_{\mathrm{g}}\right)$, the sample can develop relatively large deformation. Then, it can be fixed this temporary shape by cooling to a temperature below $T_{\mathrm{g}}$ or room temperature $\left(25^{\circ} \mathrm{C}\right)$. Figure 9 showed shape fixity at various fixing temperatures of the NGDE/PBA-a shape memory samples. From the figure, $R_{\mathrm{f}} \mathrm{s}$ of the samples were measured to be in a range of 83.1 to $84.5 \%$ at $T_{\mathrm{g}}-10^{\circ} \mathrm{C}, 96.5$ to $97.4 \%$ at $T_{\mathrm{g}}-20^{\circ} \mathrm{C}$ and 98.1 to $99.3 \%$ at $25^{\circ} \mathrm{C}$. We can see that the $R_{\mathrm{f}}$ values of all samples at various fixing temperatures decreased slightly by an increase in the BA-a contents from 30 to $50 \mathrm{~mol} \%$. The decrease in the shape fixity values with an incorporation of the 


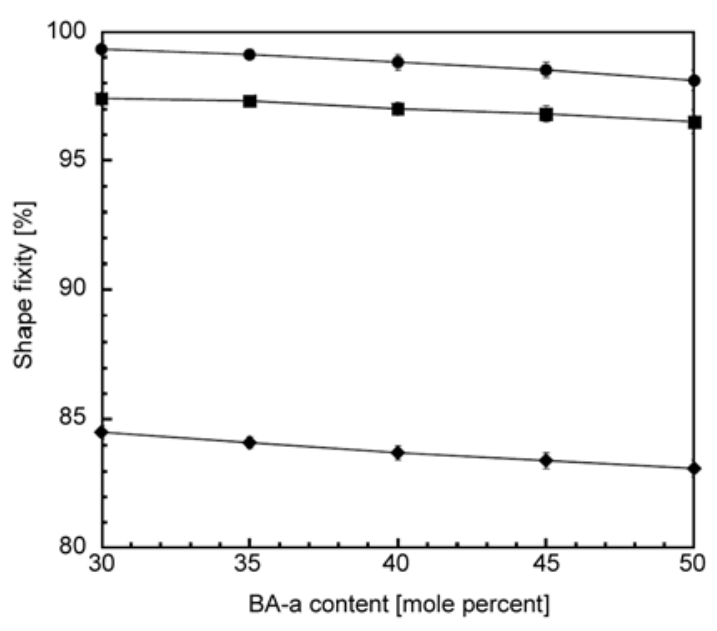

Figure 9. Effect of BA-a contents on shape fixity at different fixing temperatures of NGDE/PBA-a SMPs:

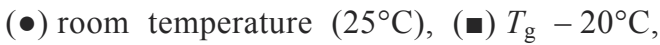
(•) $T_{\mathrm{g}}-10^{\circ} \mathrm{C}$

hard rigid phase of the shape memory polymers had also been reported by Ji et al. [15]. In their studies, the shape fixity at fixing temperature of $T_{\mathrm{g}}-20^{\circ} \mathrm{C}$ of polyurethanes (PUs) was reported to decrease from $96 \%$ to $84 \%$ with an increase of PU hard-segment content from $30 \%$ to $50 \%$.

Moreover, it was also found that $R_{\mathrm{f}}$ of the NGDE/ PBA-a SMPs comparing at the same BA-a content increased with lower fixing temperature, i.e. from $T_{\mathrm{g}}-10^{\circ} \mathrm{C}$ to $25^{\circ} \mathrm{C}$. This behavior is because some molecular chain segments were unfixed at $T_{\mathrm{g}}-10^{\circ} \mathrm{C}$. Therefore, the samples can partially restore to permanent shape that made the samples less controllable of its temporary shape. The shape fixity values at $T_{\mathrm{g}}-20^{\circ} \mathrm{C}$ and at $25^{\circ} \mathrm{C}$ are close to $100 \%$ because these fixing temperatures were sufficiently low to freeze the motion of the molecular segments. The shape fixities of our samples, i.e. about $83.1-84.5 \%$ at $T_{\mathrm{g}}-10^{\circ} \mathrm{C}$ and $96.5-97.4 \%$ at $T_{\mathrm{g}}-20^{\circ} \mathrm{C}$, are still higher than that of polyurethane SMPs (i.e. about $77 \%$ at $T_{\mathrm{g}}-10^{\circ} \mathrm{C}$ and $95 \%$ at $T_{\mathrm{g}}-20^{\circ} \mathrm{C}$ ) [47] suggesting a less chain mobility of our polymer network comparing at the same fixing temperature below their $T_{\mathrm{g}}$ above.

\subsection{Effect of BA-a contents on shape recovery behaviors of NGDE/PBA-a SMPs}

Shape recovery behaviors of the aliphatic epoxy (NGDE)/polybenzoxazine (PBA-a) SMPs were studied using a fold-deploy shape memory test. Bending deformation was widely employed for evaluating shape memory properties of polymer materials due to a large deflection being easily obtained in a range of small strain through bending [48]. Figure 10 presents snapshots of the shape recovery sequence at $T_{\mathrm{g}}+20^{\circ} \mathrm{C}$ of the sample at $40 \mathrm{~mol} \% \mathrm{BA}-\mathrm{a}$. It can be seen that the sample can fully recover its permanent shape with $100 \%$ shape recovery or with recovery angle of $180^{\circ}$. In addition, all of our SMPs, i.e. with benzoxazine resin (BA-a) contents from 30$50 \mathrm{~mol} \%$, also displayed shape recovery performance of about $100 \%$ at $T_{\mathrm{g}}+20^{\circ} \mathrm{C}$. The photographs of NGDE/PBA-a SMP at original shape, temporary shape and recovered shape at $T_{\mathrm{g}}+20^{\circ} \mathrm{C}$ was presented in Figure $4 \mathrm{~b}$. This characteristic suggests that the deformation of stable PBA-a network could be recovered completely if the NGDE/PBA-a SMPs were heated to sufficiently high temperature. In addition, it implies that the NGDE/PBA-a copolymers are covalently crosslinked to form three-dimensional network structures which become reversibly rubbery at above $T_{\mathrm{g}}$ [49].

The effect of BA-a contents on recovery angle as a function of time for the NGDE/PBA-a SMPs under a bending test at $T_{\mathrm{g}}$ and $T_{\mathrm{g}}+20^{\circ} \mathrm{C}$, are depicted in Figure 11 and Figure 12, respectively. From the figures, all samples can completely recover to their permanent shape. The recovery time of the SMPs was found to increase with increasing BA-a from 30 to $50 \mathrm{~mol} \%$, i.e. from 75 to $145 \mathrm{~s}$ at $T_{\mathrm{g}}$ and from 60 to $120 \mathrm{~s}$ at $T_{\mathrm{g}}+20^{\circ} \mathrm{C}$. Its recovery time is about the same as that of shape memory materials based on epoxy and activity polyurethane (APU) [50] showing recovery time of about $120 \mathrm{~s}$ at their $T_{\mathrm{g}}$. In addition, the curve in Figures 11 and 12 can be divided into three zones. The start stage (at a recovery angle of 0 to $50^{\circ}$ ), transition stage (a recovery angle of 50 to $150^{\circ}$ ) and terminal stage (a recovery angle of 150 to $180^{\circ}$ ). This behavior suggests that the NGDE/ PBA-a SMPs have a relative low recovery rate at the start and terminal stage. At the start stage, the release of constrained force was followed by heavy friction among molecules, thus the recovery angle slowly increased. After that, fraction force reduced under the gradual adjustment of segments results in the slopes of recovery angle is sharply as named the transition stage. At the terminal stage, the shape recovery rate becomes slower than the transition stage because the constrained force of the sample had been released due to a little of it remaining [7, 37, 51].

In addition, the shape recovery time of the samples tended to decrease with increasing the active temperature from $T_{\mathrm{g}}$ to $T_{\mathrm{g}}+20^{\circ} \mathrm{C}$. This phenomenon is 

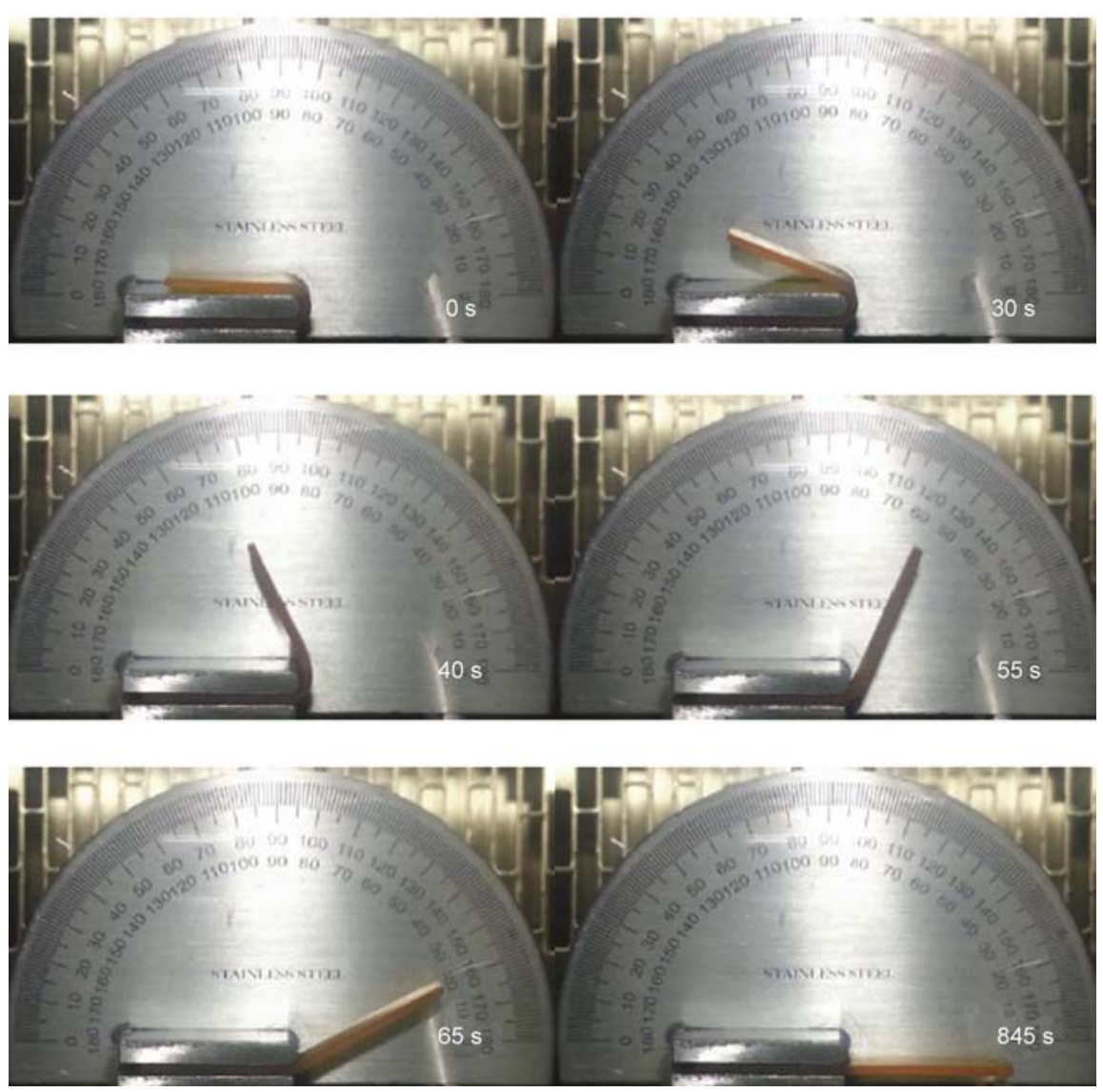

Figure 10. Series of images showed shape recovery of NGDE/PBA-a SMP with $40 \mathrm{~mol} \% \mathrm{BA}-\mathrm{a}$ at a $T_{\mathrm{g}}+20^{\circ} \mathrm{C}\left(108^{\circ} \mathrm{C}\right)$. The permanent and temporary shapes are rectangular and U-shape, respectively.

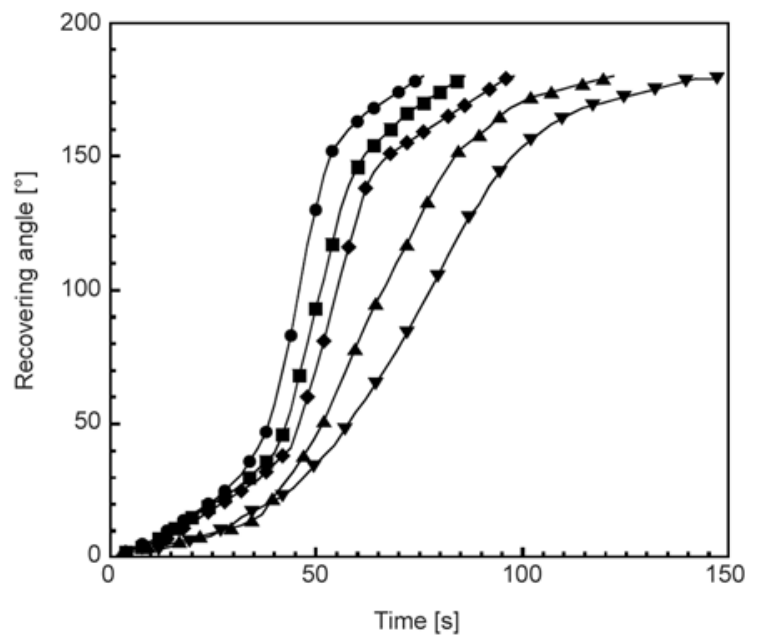

Figure 11. Recovery angle as a function of recovery time during the shape recovery process at a $T_{\mathrm{g}}$ of NGDE/PBA-a SMPs at various mole percents of BA-a: (•) $30 \mathrm{~mol} \%$, (•) $35 \mathrm{~mol} \%$, (•) $40 \mathrm{~mol} \%$, (४) $45 \mathrm{~mol} \%$, ( $\boldsymbol{\nabla}) 50 \mathrm{~mol} \%$

due to the fact that, at higher temperature, the activated molecular chain segments can move more intensely. Moreover, the shape recovery time of the samples increased with an increasing amount of BA-a content. This implied that the movement of the molecular chain segment of the NGDE/PBA-a shape

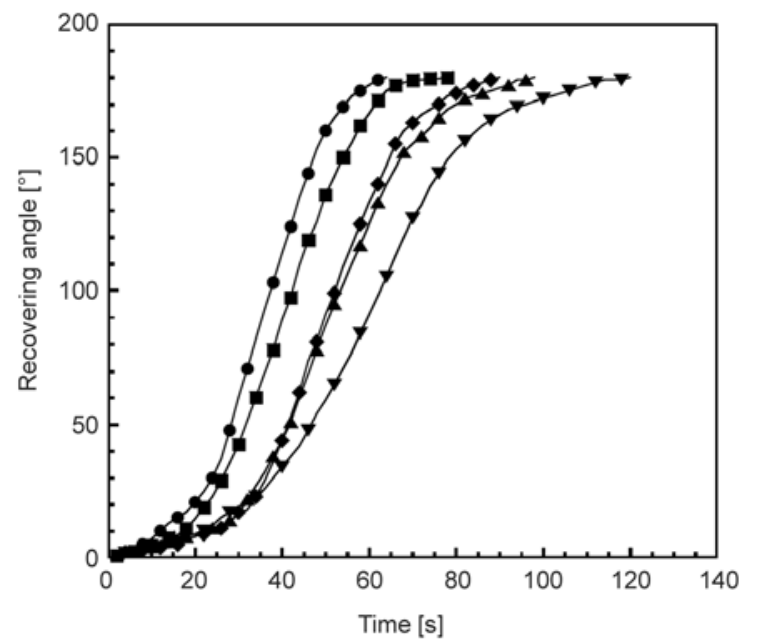

Figure 12. Recovery angle as a function of recovery time during the shape recovery process at a $T_{\mathrm{g}}+20^{\circ} \mathrm{C}$ of NGDE/PBA-a SMPs at various mole percents of $\mathrm{BA}-\mathrm{a}: \quad(\bullet) 30 \mathrm{~mol} \%, \quad$ (•) $35 \mathrm{~mol} \%$, (•) $40 \mathrm{~mol} \%$, (४ $45 \mathrm{~mol} \%$, ( $\mathbf{\nabla}) 50 \mathrm{~mol} \%$

memory samples could be more restricted with increasing BA-a content since an increasing of storage modulus at rubbery plateau was observed in the DMA results. The recovery times of our SMPs were in the same range as that of epoxy resin E-51 (WSR 618) cured by aromatic amine curing agent [37]. 
Therefore, the incorporation of the BA-a into the NGDE/PBA-a SMPs can prolong the shape recovery time thus broadening the range of application of these SMPs.

Furthermore, in order to observe the performance of the shape memory behavior over period of time for fixed temporary shape. The NGDE/PBA-a SMP at $40 \mathrm{~mol} \% \mathrm{BA}-\mathrm{a}$ was used as a representative sample to demonstrate the shape memory behavior after the time period of $20 \mathrm{~min}, 7$ days, 15 days and 30 days used to fix its temporary shape. The samples showed negligible change in its temporary shape after all time periods. In addition, the time for complete recovery to their permanent shape of these samples after heated up to $T_{\mathrm{g}}+20^{\circ} \mathrm{C}$ was $84,85,85$ and $86 \mathrm{~s}$, respectively. This result implied that the performance of the SMPs based on the NGDE/PBA-a copolymers indicates a relatively good shape memory as they can be maintained over a long period of time.

\subsection{Effect of BA-a contents on recovery stress of NGDE/PBA-a SMPs}

The experimental procedure of the recovery stress test of the aliphatic epoxy (NGDE)/polybenzoxazine (PBA-a) SMPs is depicted in Figure 13. Firstly, the sample at its permanent state was heated to $20^{\circ} \mathrm{C}$ above $T_{\mathrm{g}}\left(T_{\mathrm{g}}+{ }^{\circ} \mathrm{C}\right)$ as seen in Figure 13a. After that it was applied by flexural load during heating at $T_{\mathrm{g}}+20^{\circ} \mathrm{C}$ until its maximum deflection $\left(y_{\max }=\right.$ $10 \mathrm{~mm}$ ) as shown in Figure 13b. The deformed state of $y_{\max }=10 \mathrm{~mm}$ at $T_{\mathrm{g}}+20^{\circ} \mathrm{C}$ is almost maintained after cooling down to room temperature. Then, the sample was held at room temperature under unloaded condition for $20 \mathrm{~min}$ as presented in Figure 13c. Finally, the sample was heated to $T_{\mathrm{g}}+20^{\circ} \mathrm{C}$ by maintaining the fixed deflection constant as can be seen in Figure 13d. Recovery stress during heating was masured from the transition stage of the shape-fixed stage to the recovery shape stage.

The recovery stress versus time of the SMPs is shown in Figure 14. The maximum recovery stress of the samples were observed to be $0.25,0.39,0.62,0.98$ and $1.59 \mathrm{MPa}$ at BA-a contents ranging from 30 , $35,40,45$ and $50 \mathrm{~mol} \%$, respectively. As a result, it could be seen that content of the BA-a is an efficient way to increase recovery stress of the SMPs. Recently, the recovery stress obtained from the thermomechanical analysis (TMA) experiments of shape memory polymer based on styrene cured with benzoyl peroxide has been studied [17, 52-54]. It a)
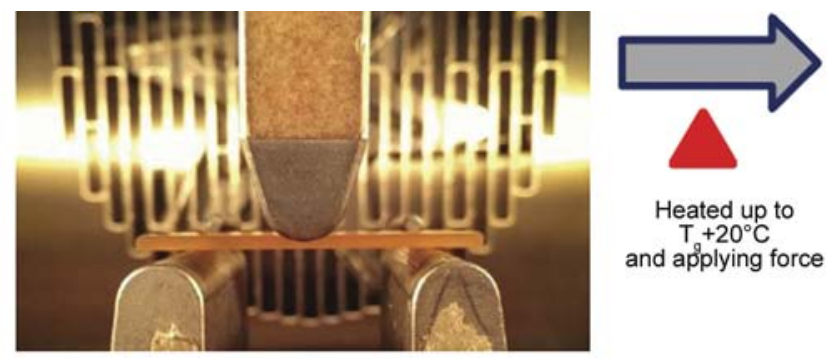

b)

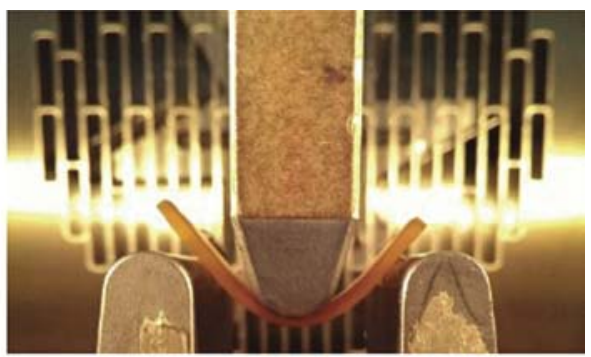

c)

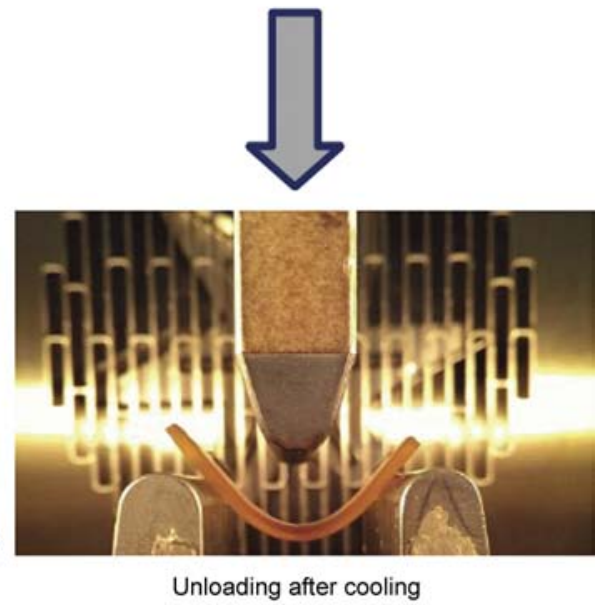

Figure 13. Photographs showing various states of bending in recovery stress process for NGDE/PBA-a SMPs: (a) permanent state of the sample at room temperature, (b) deformed state with $y_{\max }=10 \mathrm{~mm}$ at $T_{\mathrm{g}}+20^{\circ} \mathrm{C}$, (c) shape-fixed state after cooling followed by unloading at room temperature for $20 \mathrm{~min}$ and (d) shape-recovered state after heating up to $T_{\mathrm{g}}+20^{\circ} \mathrm{C}$ and stress during reheating was measured 


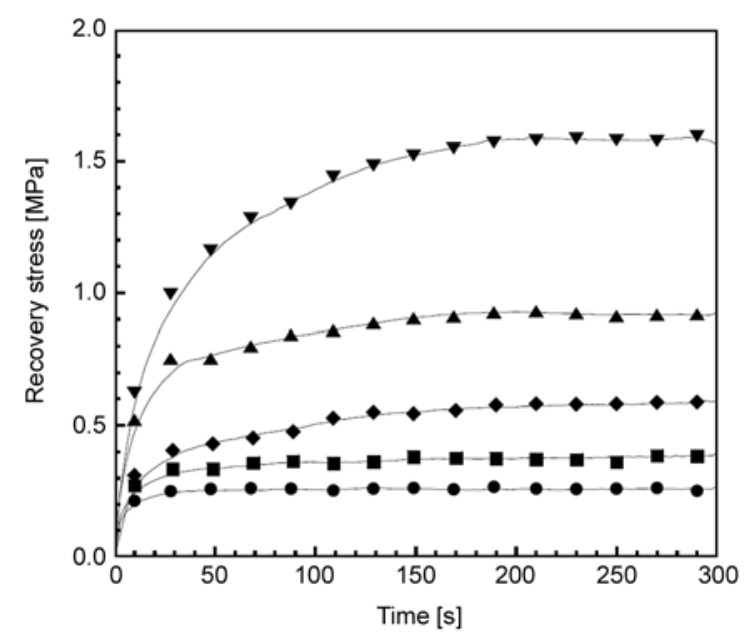

Figure 14. Recovery stress versus time of NGDE/PBA-a SMPs at various mole percents of BA-a: (•) $30 \mathrm{~mol} \%$, (घ) $35 \mathrm{~mol} \%, \quad$ (•) $40 \mathrm{~mol} \%$, (४) $45 \mathrm{~mol} \%$, ( $\mathbf{v}) 50 \mathrm{~mol} \%$

has been reported that the recovery stress obtained from the TMA experiments of the commercial styrene cured with benzoyl peroxide based shape memory polymer (Veriflex VF62 of CRG Industries in Dayton, $\mathrm{OH}$ ) was reported to be about $0.05 \mathrm{MPa}$ [17]. Therefore, some of our SMPs showed a significantly high shape recovery stress that could result in complete expansive shape recovery within a spatially constraint environment such as narrowed or middlesized vessel. In addition,the increase of the recovery stress was observed in shape memory epoxy nanocomposites [12]. It was found that at maximum $\mathrm{SiC}$ nano powder filler loading ( $20 \mathrm{wt} \%$ ), the recovery stress of the nanocomposite was observed to be $1.5 \mathrm{MPa}$, i.e. 1 time greater than that of the neat epoxy SMP, having the recovery stress of about $0.8 \mathrm{MPa}$. Interestingly, NGDE/PBA-a SMPs can provide recovery stress about 6 times from $0.25 \mathrm{MPa}$ at $30 \mathrm{~mol} \% \mathrm{BA}$-a to $1.59 \mathrm{MPa}$ at $50 \mathrm{~mol} \% \mathrm{BA}$-a, which is substantially more than that of the epoxy SMPs nanocomposites. This is to say that the increasing of the recovery stress of the NGDE/PBA-a SMPs was due to the presence of the BA-a in the copolymers, resulting in increasing crosslink density that can enhance storage modulus at rubbery state of the copolymers [49]. Thus, the SMPs based on the polybenzoxazine is a good candidate to use for deployable structures, such as hinge [55].

\section{Conclusions}

Polybenzoxazine blending with aliphatic epoxy based shape memory polymer (SMP) is developed. The effect of benzoxazine resin content in aliphatic epoxy based SMPs on thermal stability, mechanical properties and shape memory properties were characterized. An incorporation of the benzoxazine resin in the aliphatic epoxy based SMP resulted in an increase of glass transition temperature, storage modulus, crosslink density and recovery stress of the SMPs. The same trend was also observed in their flexural strength and modulus at room temperature as well as in the rubbery state. Interestingly, the obtained SMPs provided an outstanding shape fixity value up to $99 \%$ at room temperature. At different active temperatures, i.e. $T_{\mathrm{g}}$ and $T_{\mathrm{g}}+20^{\circ} \mathrm{C}$, all SMPs needed only 1-3 minutes to fully recover to their permanent shape. Moreover, the addition of the benzoxazine fraction can prolong the shape recovery time of the resulting SMPs. Therefore, the obtained aliphatic epoxy/polybenzoxazine SMPs are attractive as shape memory materials to be used in a broad range of applications such as hinge or deployable structure.

\section{Acknowledgements}

This research is supported by the 90th Anniversary of Chulalongkorn University Fund and by the Ratchadaphiseksomphot Endowment Fund 2014 of Chulalongkorn University (CU-57-056-EN). Prof. S. Hiziroglu is also acknowledged for his valuable comments on this work.

\section{References}

[1] Liu Y., Du H., Liu L., Leng J.: Shape memory polymers and their composites in aerospace applications: A review. Smart Materials and Structures, 23, 023001/1023001/22 (2014).

DOI: $10.1088 / 0964-1726 / 23 / 2 / 023001$

[2] Kolesov I. S., Radusch H-J.: Multiple shape-memory behavior and thermal-mechanical properties of peroxide cross-linked blends of linear and short-chain branched polyethylenes. Express Polymer Letters, 2, 461-473 (2008). DOI: $10.3144 /$ expresspolymlett.2008.56

[3] Kang S. M., Lee S. J., Kim B. K.: Shape memory polyurethane foams. Express Polymer Letters, 6, 6369 (2012).

DOI: $10.3144 /$ expresspolymlett.2012.7

[4] Ehrenstein G. W.: Polymeric materials: Structure, properties, applications. Hanser, Munich (2001).

[5] Liu L., Cai W.: Novel copolyester for a shape-memory biodegradable material in vivo. Materials Letters, 63, 1656-1658 (2009). DOI: $10.1016 /$ j.matlet.2009.04.037

[6] Fan K., Huang W. M., Wang C. C., Ding Z., Zhao Y., Purnawali H., Liew K. C., Zheng L. X.: Water-responsive shape memory hybrid: Design concept and demonstration. Express Polymer Letters, 5, 409-416 (2011). DOI: $10.3144 /$ expresspolymlett.2011.40 
[7] Rimdusit S., Lohwerathama M., Hemvichian K., Kasemsiri P., Dueramae I.: Shape memory polymers from benzoxazine-modified epoxy. Smart Materials and Structures, 22, 075033/1-075033/12 (2013). DOI: $10.1088 / 0964-1726 / 22 / 7 / 075033$

[8] Leng J., Lan X., Liu Y., Du S.: Shape-memory polymers and their composites: Stimulus methods and applications. Progress in Materials Science, 56, 1077-1135 (2011). DOI: 10.1016/j.pmatsci.2011.03.001

[9] Karger-Kocsis J., Kéki S.: Biodegradable polyesterbased shape memory polymers: Concepts of (supra) molecular architecturing. Express Polymer Letters, 8, 397-412 (2014).

DOI: $10.3144 /$ expresspolymlett.2014.44

[10] Hu J., Zhu Y., Huang H., Lu J.: Recent advances in shape-memory polymers: Structure, mechanism, functionality, modeling and applications. Progress in Polymer Science, 37, 1720-1763 (2012).

DOI: $10.1016 /$ j.progpolymsci.2012.06.001

[11] Meng Q., Hu J.: A review of shape memory polymer composites and blends. Composites Part A: Applied Science and Manufacturing, 40, 1661-1672 (2009). DOI: 10.1016/j.compositesa.2009.08.011

[12] Liu Y., Gall K., Dunn M. L., McCluskey P.: Thermomechanics of shape memory polymer nanocomposites. Mechanics of Materials, 36, 929-940 (2004).

DOI: $10.1016 /$ j.mechmat.2003.08.012

[13] Santhosh Kumar K. S., Biju R., Reghunadhan Nair C. P.: Progress in shape memory epoxy resins. Reactive and Functional Polymers, 73, 421-430 (2013). DOI: $10.1016 /$ j.reactfunctpolym.2012.06.009

[14] Meng H., Li G.: A review of stimuli-responsive shape memory polymer composites. Polymer, 54, 2199-2221 (2013).

DOI: $10.1016 /$ j.polymer.2013.02.023

[15] Ji F. L., Hu J. L., Li T. C., Wong Y. W.: Morphology and shape memory effect of segmented polyurethanes. Part I: With crystalline reversible phase. Polymer, 48, 5133-5145 (2007).

DOI: $10.1016 /$ j.polymer.2007.06.032

[16] Havens E., Snyder E. A., Tong T. H.: Light actived shapem polymers and associated applications. Proceeding of SPIE, Smart Structures and Materials, 5762, 48-55 (2005).

DOI: $10.1117 / 12.606109$

[17] Ivens J., Urbanus M., De Smet C.: Shape recovery in a thermoset shape memory polymer and its fabric-reinforced composites. Express Polymer Letters, 5, 254261 (2011).

DOI: $10.3144 /$ expresspolymlett.2011.25

[18] Dorigato A., Giusti G., Bondioli F., Pegoretti A.: Electrically conductive epoxy nanocomposites containing carbonaceous fillers and in-situ generated silver nanoparticles. Express Polymer Letters, 7, 673-682 (2013). DOI: $10.3144 /$ expresspolymlett.2013.64
[19] Fejős M., Karger-Kocsis J.: Shape memory performance of asymmetrically reinforced epoxy/carbon fibre fabric composites in flexure. Express Polymer Letters, 7, 528-534 (2013).

DOI: 10.3144 /expresspolymlett.2013.49

[20] Xie T., Rousseau I. A.: Facile tailoring of thermal transition temperatures of epoxy shape memory polymers. Polymer, 50, 1852-1856 (2009).

DOI: $10.1016 /$ j.polymer.2009.02.035

[21] Zheng N., Fang G., Cao Z., Zhao Q., Xie T.: High strain epoxy shape memory polymer. Polymer Chemistry, 6 , 3046-3053 (2015).

DOI: $10.1039 / \mathrm{C} 5 \mathrm{PY} 00172 \mathrm{~B}$

[22] Wright W. W.: High performance polymers and composites. Wiley, New York (1991).

[23] Ishida H., Agag T.: Handbook of benzoxazine resins. Elsevier, New York (2011).

[24] Ishida H., Rimdusit S.: Very high thermal conductivity obtained by boron nitride-filled polybenzoxazine. Thermochimica Acta, 320, 177-186 (1998).

DOI: $10.1016 / \mathrm{S} 0040-6031(98) 00463-8$

[25] Rimdusit S., Tanthapanichakoon W., Jubsilp C.: High performance wood composites from highly filled polybenzoxazine. Journal of Applied Polymer Science, 99, 1240-1253 (2006).

DOI: $10.1002 /$ app. 22607

[26] Jubsilp C., Takeichi T., Hiziroglu S., Rimdusit S.: High performance wood composites based on benzoxazine-epoxy alloys. Bioresource Technology, 99, 88808886 (2008).

DOI: 10.1016/j.biortech.2008.04.057

[27] Rimdusit S., Jubsilp C., Tiptipakorn S.: Alloys and composites of polybenzoxazines: Properties and applications. Springer, Singapore (2013).

[28] Jubsilp C., Rimdusit S., Takeichi T.: Aniline-based polybenzoxazine and their copolymers or composites: Molecular design and potential applications. in 'Aniline: structure/phyxical properties, reactions and environmental effects' (eds.: Hernandez K., Holloway M.) Nova Science Publishers, New York, 55-90 (2013).

[29] Jubsilp C., Punson K., Takeichi T., Rimdusit S.: Curing kinetics of benzoxazine-epoxy copolymer investigated by non-isothermal differential scanning calorimetry. Polymer Degradation and Stability, 95, 918-924 (2010).

DOI: 10.1016/j.polymdegradstab.2010.03.029

[30] Rimdusit S., Kunopast P., Dueramae I.: Thermomechanical properties of arylamine-based benzoxazine resins alloyed with epoxy resin. Polymer Engineering and Science, 51, 1797-1807 (2011).

DOI: 10.1002/pen.21969

[31] Kimura H., Matsumoto A., Hasegawa K., Ohtsuka K., Fukuda A.: Epoxy resin cured by bisphenol A based benzoxazine. Journal of Applied Polymer Science, 68, 1903-1910 (1998).

DOI: $10.1002 /($ SICI) 1097-4628(19980620)68:12<1903 $\because: \mathrm{AID}-\mathrm{APP} 2>3.0 . \mathrm{CO} ; 2-\mathrm{P}$ 
[32] Erden N., Jana S. C.: Synthesis and characterization of shape-memory polyurethane-polybenzoxazine compounds. Macromolecular Chemistry and Physics, 214, 1225-1237 (2013).

DOI: $10.1002 /$ macp. 201200315

[33] Ishida H.: Process for preparation of benzoxazine compounds in solventless systems. U.S. Patent 5543516, USA (1996).

[34] Lan X., Liu Y., Lv H., Wang X., Leng J., Du S.: Fiber reinforced shape-memory polymer composite and its application in a deployable hinge. Smart Materials and Structures, 18, 024002/1-024002/6 (2009). DOI: $10.1088 / 0964-1726 / 18 / 2 / 024002$

[35] Tobushi H., Hayashi S., Hoshio K., Makino Y., Miwa N.: Bending actuation characteristics of shape memory composite with SMA and SMP. Journal of Intelligent Material Systems and Structures, 17, 1075-1081 (2006). DOI: $10.1177 / 1045389 X 06064885$

[36] Rimdusit S., Ishida H.: Development of new class of electronic packaging materials based on ternary systems of benzoxazine, epoxy, and phenolic resins. Polymer, 41, 7941-7949 (2000). DOI: 10.1016/S0032-3861(00)00164-6

[37] Liu Y., Han C., Tan H., Du X.: Thermal, mechanical and shape memory properties of shape memory epoxy resin. Materials Science and Engineering: A, 527, 2510-2514 (2010).

DOI: $10.1016 /$ j.msea.2009.12.014

[38] Jubsilp C., Ramsiri B., Rimdusit S.: Effects of aromatic carboxylic dianhydrides on thermomechanical properties of polybenzoxazine-dianhydride copolymers. Polymer Engineering and Science, 52, 1640-1648 (2012).

DOI: $10.1002 /$ pen.23107

[39] Silverstein R. M., Bassler G. C., Morrill T. C.: Spectrometric identification of organic compounds. Wiley, New York (1981).

[40] Schuh C., Schuh K., Lechmann M. C., Garnier L., Kraft A.: Shape-memory properties of segmented polymers containing aramid hard segments and polycaprolactone soft segments. Polymers, 2, 71-85 (2010). DOI: $10.3390 /$ polym2020071

[41] Cao Y-P., Guan Y., Du J., Peng Y-X., Yip C. W., Chan A. S. C.: Polymer network-poly(ethylene glycol) complexes with shape memory effect. Chinese Journal of Polymer Science, 21, 29-33 (2003).

[42] Rimdusit S., Pirstpindvong S., Tanthapanichakoon W., Damrongsakkul S.: Toughening of polybenzoxazine by alloying with urethane prepolymer and flexible epoxy: A comparative study. Polymer Engineering and Science, 45, 288-296 (2005).

DOI: $10.1002 /$ pen. 20273

[43] Barnell T., Margraf T. W.: Healable, shape memory polymer for reflexive composites. in 'SAMPE 2008 52nd International SAMPE Symposium, Baltimore, USA' p. 10 (2008).
[44] Rimdusit S., Tiptipakorn S., Jubsilp C., Takeichi T.: Polybenzoxazine alloys and blends: Some unique properties and applications. Reactive and Functional Polymers, 73, 369-380 (2013).

DOI: 10.1016/j.reactfunctpolym.2012.04.022

[45] Biju R., Gouri C., Reghunadhan Nair C. P.: Shape memory polymers based on cyanate ester-epoxy-poly (tetramethyleneoxide) co-reacted system. European Polymer Journal, 48, 499-511 (2012).

DOI: $10.1016 /$ j.eurpolymj.2011.11.019

[46] Beblo R., Gross K., Mauck Weiland L.: Mechanical and curing properties of a styrene-based shape memory polymer. Journal of Intelligent Material Systems and Structures, 21, 677-683 (2010).

DOI: $10.1177 / 1045389 X 10364860$

[47] Hu J. L., Ji F. L., Wong Y. W.: Dependency of the shape memory properties of a polyurethane upon thermomechanical cyclic conditions. Polymer International, 54, 600-605 (2005).

DOI: $10.1002 /$ pi. 1745

[48] Ratna D., Karger-Kocsis J.: Shape memory polymer system of semi-interpenetrating network structure composed of crosslinked poly (methyl methacrylate) and poly (ethylene oxide). Polymer, 52, 1063-1070 (2011). DOI: $10.1016 /$ j.polymer.2010.12.054

[49] Rousseau I. A.: Challenges of shape memory polymers: A review of the progress toward overcoming SMP's limitations. Polymer Engineering and Science, 48, 2075-2089 (2008). DOI: $10.1002 /$ pen.21213

[50] Liu Y., Sun H., Tan H., Du X.: Modified shape memory epoxy resin composites by blending activity polyurethane. Journal of Applied Polymer Science, 127, 3152-3158 (2013).

DOI: $10.1002 / a p p .37688$

[51] Fan M., Yu H., Li X., Cheng J., Zhang J.: Thermomechanical and shape-memory properties of epoxy-based shape-memory polymer using diglycidyl ether of ethoxylated bisphenol-A. Smart Materials and Structures, 22, 055034/1-055034/7 (2013).

DOI: $10.1088 / 0964-1726 / 22 / 5 / 055034$

[52] Nji J., Li G.: A biomimic shape memory polymer based self-healing particulate composite. Polymer, 51, 6021-6029 (2010).

DOI: $10.1016 /$ j.polymer.2010.10.021

[53] Li G., Uppu N.: Shape memory polymer based selfhealing syntactic foam: 3-D confined thermomechanical characterization. Composites Science and Technology, 70, 1419-1427 (2010).

DOI: $10.1016 /$ j.compscitech.2010.04.026

[54] Li G., Nettles D.: Thermomechanical characterization of a shape memory polymer based self-repairing syntactic foam. Polymer, 51, 755-762 (2010).

DOI: 10.1016/j.polymer.2009.12.002

[55] Tandon G. P., Goecke K., Cable K., Baur J.: Environmental durability of fabric-reinforced shape-memory polymer composites. Journal of Intelligent Material Systems and Structures, 21, 1365-1381 (2010). DOI: $\underline{10.1177 / 1045389 X 10386265}$ 